\title{
Arsenic and antimony concentrations in Chinese typical farmland soils
}

\author{
A. Parvez ${ }^{1}$, C.L. $\mathrm{Ma}^{1}$, Q.Y. Zhong ${ }^{1}$, C.Y. $\mathrm{Lin}^{1}$, Y.B. $\mathrm{Ma}^{2}$ \& M.C. $\mathrm{He}^{1}$ \\ ${ }^{1}$ State Key Laboratory of Water Environment Simulation, School of Environment, \\ Beijing Normal University, Beijing, P.R. China \\ ${ }^{2}$ Institute of Agricultural Resources and Regional Planning, \\ Chinese Academy of Agricultural Sciences, Beijing, P.R. China
}

\begin{abstract}
The pollution extent by heavy metals in soils is dependent on their total contents, chemical speciation, sources, and some soil physicochemical factors affected their geochemical behaviors. The difficulty in characterization of soil, and current lack of ecological risk assessment methods for heavy metals in farmland soils in China are to be addressed. This study aimed are to investigate the distribution of Arsenic (As) and Antimony ( $\mathrm{Sb}$ ) in different soils collected from 21 provinces of China, and to assess the total content of As and $\mathrm{Sb}$ in the soil samples. The present study evaluates the understanding of differences in soil bio-toxicity effects against different heavy metals. The total content of $\mathrm{As}$ and $\mathrm{Sb}$ in different soils was extracted by double acid digestion $\left(\mathrm{HNO}_{3}\right.$ and $\left.\mathrm{HCl}\right)$. The concentration was measured using $\mathrm{HG}-\mathrm{AFS}$ technique. It provides the basic information about the presence of these toxic metals in different types of soils around China.
\end{abstract}

\section{INTRODUCTION}

Arsenic is a commonly encountered contaminant in the environments because of its release during industrial, mining, and agricultural activities (Smedley \& Kinniburgh, 2002). The toxicity and mobility of arsenic in soil environments is a function of its oxidation state and its sorption to soil minerals and organic matter (Charlet et al., 2011). Antimony is a toxic element, and excess intake results in many diseases in humans, such as cancers, cardiovascular disease, liver disease and respiratory disease (WHO, 2003). China has the most abundant $\mathrm{Sb}$ resources of any country in the World (He et al., 2012). Soil contamination by As and $\mathrm{Sb}$ is suspected to cause health problems in some regions in China. For example, residents of antimony mining area in the south Guizhou province in China are subjected to long-term $\mathrm{Sb}$ exposure, and liver cirrhosis is the primary cause of death (Cen et al., 2007).

\section{EXPERIMENTAL METHODS}

\subsection{Soil sampling and extraction method}

Soil samples from 21 provinces of China were airdried, sifted to remove stone and debris, then ground to pass through a 20 -mesh sieve $(0.99 \mathrm{~mm}$ in particle size). Approximately $0.1 \mathrm{~g}$ of this fine powder from each sample was accurately weighed into a glass tube $(25 \mathrm{~mL})$ containing $3 \mathrm{~mL}$ concentrated $\mathrm{HNO}_{3}$ and $1 \mathrm{~mL} \mathrm{HCl}$ and left overnight. Samples will be digested for $2 \mathrm{~h}$ in a water bath at $90^{\circ} \mathrm{C}$, after which the supernatants were obtained via centrifugation and filtration. $\mathrm{As}$ and $\mathrm{Sb}$ was measured using a hydride generation atomic fluorescence spectrometer (HG-AFS) (Wei et al., 2011). Blanks, duplicated samples and soil standard reference materials (Centre for Reference Materials, China) were used to verify the accuracy of the analysis.

\subsection{Analytical technique}

Numerous analytical techniques and experimental approaches have been proposed in the last two decades to identify and measure $\mathrm{As}$ and $\mathrm{Sb}$ aimed at obtaining reliable results and correct evaluations in the field of environmental chemistry. Atomic fluorescence spectroscopy coupled to HG has received increasing attention because its suitability for As and Sb determination at trace levels due to its high sensitivity, wide dynamic range (4-6 orders of magnitude), simplicity and very low instrumental cost (Chen et al., 2003; Miravet et al., 2005; Zhang et al., 2005).

The QA/QC included the calibration, blanks and using the reference materials. Initial calibration was performed before all the samples. The calibration curve yielded correlation coefficient of 0.998 . QC samples were prepared and analyzed with each set of soil samples for As and $\mathrm{Sb}$ detection. The samples were gone through the same sample preparation method in the same manner to ensure the evaluation of extraction procedure. The recovery percentage for reference materials ranged from $88 \%$ to $97 \%$. 


\section{RESULTS AND DISCUSSION}

\subsection{Arsenic}

The concentrations of As are in the range of 1.688 and $10.28 \mathrm{mg} \mathrm{kg}^{-1}$ (mean $5.575 \mathrm{mg} \mathrm{kg}^{-1}$ ). The soil of Xinjiang soil is presenting a highest concentration of As (10.28 mg kg-1) among the different farmland soils of China. The minimum amount of As is found in the sample of Jilin soil $\left(1.688 \mathrm{mg} \mathrm{kg}^{-1}\right)$. The binding of As via ternary complexes and mobile colloids has been considered the most important but not the sole driver of As mobility in soils. The total content of As gives the information about the presence of As concentration as a whole. However, the environmental availability and toxicological effects of As depend on its speciation, the knowledge of the oxidation state of As in soils is essential for the risk assessment.

\subsection{Antimony}

Soil is the main plant-developing medium; it is also a major contaminant sink in various ways: fertilizers and amendments inputs, aerial deposition, and water percolation. Therefore, the concentration of $\mathrm{Sb}$ is varying in different provinces of China (0.091$0.521 \mathrm{mg} \mathrm{kg}^{-1}$ ). The highest concentration of $\mathrm{Sb}$ was found in the soil of Anhui province $\left(0.521 \mathrm{mg} \mathrm{kg}^{-1}\right)$. The soil of Chongqing city showed the minimum concentration of $\mathrm{Sb}$ as shown in Table 1.

Table 1. Concentration of arsenic and antimony in different soils $\left(\mathrm{mg} \mathrm{kg}^{-1}\right)$.

\begin{tabular}{llc}
\hline Province & Sb & As \\
\hline Hainan & 0.100 & 8.560 \\
Guangdong & 0.274 & 6.770 \\
Hunan & 0.266 & 3.779 \\
Yunnan & 0.331 & 4.735 \\
Jiangsu & 0.207 & 3.746 \\
Zhejiang & 0.128 & 5.290 \\
Anhui & 0.521 & 2.267 \\
Jiangxi & 0.260 & 6.052 \\
Sìchuan & 0.211 & 4.393 \\
Chongqing & 0.091 & 6.119 \\
Shanxi & 0.224 & 4.427 \\
Shandong & 0.140 & 6.431 \\
Shanxi & 0.372 & 9.809 \\
Hubei & 0.309 & 7.140 \\
Henan & 0.170 & 5.898 \\
Hebbi & 0.173 & 7.420 \\
Beijing & 0.351 & 3.734 \\
Ningxia & 0.252 & 3.295 \\
Xinjiang & 0.150 & 10.28 \\
Jilin & 0.179 & 1.688 \\
Heilongjiang & 0.213 & 5.245 \\
\hline
\end{tabular}

\section{CONCLUSIONS}

The present study gathers the current state of knowledge on As and $\mathrm{Sb}$ concentrations in farmland soils of China. The concentration may vary according to the difference in physico-chemical properties of soil. The study helped to develop the soil heavy metal risk assessment methods that will contribute to China's farmland soil protection and food safety. It has an important social value, which can provide technical guidance for farmland soil remediation.

\section{ACKNOWLEDGEMENTS}

This work was supported by the project of "Research on Migration/Transformation and Safety Threshold of Heavy Metals in Farmland Systems", National Key Research and Development Program of China (2016YFD0800405) and the National Natural Science Foundation of China (21477008).

\section{REFERENCES}

Cen, R.G., Li, B., Wei, S.Y., Mo, X.J. \& Zhang, L. 2007. Investigation on correlation between chronic antimony poisoning and liver fibrosis. Labeled Immunoass. Clin. Med. 14(2): 106-107.

Charlet, L., Morin, G., Rose, J., Wang, Y., Auffan, M., Burnol, A. \& Fernandez-Martinez, A. 2011. Reactivity at (nano) particle-water interfaces, redox processes, and arsenic transport in the environment, C.R. Geosci. 343(2-3): 123-139.

Chen, B., Krachler, M. \& Shotyk, W. 2003. Determination of antimony in plant and peat samples by hydride generation-atomic fluorescence spectrometry (HG-AFS). J. Anal. Atomic Spectrom. 18(10): 1256-1262.

He, M., Wang, X., Wu, F. \& Fu, Z. 2012. Antimony pollution in China. Sci. Total Environ. 421-422: 41-50.

Miravet, R., Bonilla, E., Lopez-Sanchez, J.F., \& Rubio, R. 2005. Antimony speciation in terrestrial plants. Comparative studies on extraction methods. J. Environ. Monitor. 7(12): 1207-1213.

Smedley, P.L. \& Kinniburgh, D.G. 2002. A review of the source, behaviour, and distribution of arsenic in natural waters. Appl. Geochem. 17(5): 517-568.

Wei, C., Deng, Q., Wu, F., Fu, Z. \& Xu, L. 2011. Arsenic, antimony, and bismuth uptake and accumulation by plants in an old antimony mine, China. Biol. Trace Elem. Res. 144(1-3): 1150-1158.

WHO 2003. Antimony in Drinking-Water: Background Document for Preparation of WHO Guidelines for DrinkingWater Quality. WHO/SDE/WSH/03.04/74. World Health Organization, Geneva.

Zhang, W.B., Gan, W.E. \& Lin, X.Q. 2005. Electrochemical hydride generation atomic fluorescence spectrometry for the simultaneous determination of arsenic and antimony in Chinese medicine samples. Anal. Chim. Acta 539(1): 335-340. 